\title{
Process and Product: Recirculating Hydroponics and Bioactive Compounds in a Controlled Environment
}

\author{
Gary W. Stutte \\ Dynamac Corporation, Space Life Sciences Laboratory, Kennedy Space Center, FL, 32899
}

\begin{abstract}
Additional index words. Solanum tuberosum L., recirculating hydroponics, potatoes, bioregulators, medicinal crops, bioregenerative life support

Summary. NASA has investigated the use of recirculating nutrient film technique (NFT) systems to grow higher plants on long-duration space missions for many years and has demonstrated the feasibility of using recirculating systems on numerous crop species. A long duration (418-day) experiment was conducted at Kennedy Space Center, Fla., to evaluate the feasibility of using recirculating hydroponics for the continuous production of Solanum tuberosum L. 'Norland'. The productivity of four sequential batch plantings was compared to staggered harvest and plantings. The accumulation of bioactive organic compounds in the nutrient solution resulted in reduced plant height, induced early tuber formation, and increased harvest index of the crops in both production systems. The changes in crop development were managed by increasing planting density and reducing cycle time to sustain production efficiency.
\end{abstract}

The objectives of this paper are to describe how recirculating hydroponic systems have been applied to NASA's specialized plant production activities, provide an example of the how the accumulation of bioactive compounds in the nutrient solution impacts crop development, and identify challenges and opportunities associated with recirculating hydroponic systems.

NASA has been interested in the use of higher plants as a component of a bioregenerative life support system (BLSS) to regenerate the atmosphere, purify water, and produce food during long-duration space missions for over 40 years (Halstead and Durcher, 1987; Miller and Ward, 1966; Myers, 1954; Wheeler, 2001). A number of different crops have been recommended for use in a BLSS (Goins et al., 2003; Hoff et al., 1982; Salisbury and Clark, 1996; Tibbitts and Alford, 1982). Research at Kennedy Space Center (KSC) using recirculating hydroponics to evaluate higher plants in a BLSS was initiated as part of the Controlled Ecological Life Support (CELSS) program in the mid-1980s and has subsequently evaluated many of these crops in controlled environment conditions (Wheeler et al., 1996. 2003).

The primary test bed of the NASA CELSS project between 1988 and 1997 was the Biomass Production Chamber (BPC), an atmospherically closed chamber that had been converted from a hypobaric testbed during the Mercury Program (Prince and Knott, 1989). The BPC provided $20 \mathrm{M}^{2}$ of growing area in a $113 \mathrm{~m}^{3}$ volume. The chamber had four growing levels, each with an independent nutrient tank for recirculating hydroponics (Prince and Knott, 1989). A number of staple crops were grown in these chambers between 1988 and 1996, including wheat, soybean, potato (Solanum tuberosum L.), bib lettuce, and tomato (Wheeler et al., 1996, 2003).

Received for publication 4 Oct. 2005. Accepted for publication 21 Nov. 2005. This research was supported in part by NASA's Life Science Services Contract (NAS 10-02001) at Kennedy Space Center, Fla. Mention of a trademark, proprietary product, or vendor does not constitute a guarantee or warranty by either NASA or Dynamac Corporation.

To whom reprint requests should be sent; e-mail stuttgw@kscems.ksc.nasa.gov.
In addition to the closed system tests a number of other additional horticultural crops have been grown using recirculating hydroponics. These have included romaine lettuce, spinach, chard, green onion, cherry tomato, bell pepper, pea, green bean, dry bean and strawberry. Below-ground crops produced in recirculating nutrient solution include radish, carrot, white potato, sweetpotato and peanut. The list of species and cultivars evaluated at KSC are summarized in Table 1.

The use of higher plants in a bioregenerative life support system is desirable because they remove toxic $\mathrm{CO}_{2}$, replenish $\mathrm{O}_{2}$ and purify waste water while generating food for the crew (Wheeler et al., 2001). Controlled environment chambers are used to simulate environmental conditions that would be experienced on a spacecraft and possible planetary surface greenhouses. Controlled environment chambers also provide the precise control of air temperature, relative humidity, $\mathrm{CO}_{2}$ concentration, light quality, light intensity and photoperiod that enable the unique aspects of closed environments to be explored. By using recirculating hydroponics in these chambers, precise control of nutrient composition, $\mathrm{pH}$, EC, and temperature is also achieved (Stutte and Sager, 1995).

The use of recirculating hydroponic systems creates a unique environment for the root system and presents several challenges for crop management. The primary advantages are that water usage is minimized, nutrient loss is reduced, and control of $\mathrm{EC}, \mathrm{pH}$, and flow rate is achieved (Berry and Knight, 1997; Graves, 1983; Resh, 1989). In recirculating hydroponic production of a monoculture, all the plants share a common solution containing inorganic nutrients as well as organic exudates produced by root systems and rhizosphere microorganisms. In recirculating hydroponic culture of mixed crops, the shared solution may result in competition for nutrients at different stages of development, or the appearance of allelopathic responses, that will reduce yields.

It is estimated that up to $10 \%$ of the total carbon fixed by a plant may be excreted by the root system. The production and accumulation of these organic compounds is not well understood, although compounds as diverse as organic acids, phenols, glycoproteins and flavones have been reported (Kaufman et al., 1999). Tannins and humic acids have also been reported to be leached from root systems or inedible biomass (Gaspar et al., 1999) and may enhance the uptake of micronutrients (Mackowiak et al., 2001). Although the biological activity of most of these natural products is unknown, it is clear than many of these compounds have biological activity that can impact microbe, plant, and animal physiology (Cutler and Cutler, 1999; Stutte, 1999).

The accumulation of bioactive compounds in the hydroponic nutrient solution can affect crop productivity in intensive, continuous crop production systems (Stutte, 1999; Stutte and Sager, 1995). The following section describes a long-term experiment at NASA's Kennedy Space Center that was performed to evaluate the feasibility of sustained production of 'Norland' white potato in recirculating hydroponic culture (Stutte et al., 1999). This experiment is described to illustrate the issues and opportunities that continuous production systems present.

\section{Continuous Production of Potato (418-d Experiment)}

An experiment was initiated in the BPC at $\mathrm{KSC}$ to test the hypothesis that staggered production systems were as efficient as batch production systems for long-duration missions in a closed environment (Stutte et al., 1999). The control treatment was a 104- to 105-d 5$\mathrm{m}^{2}$ batch planting of potato in which the entire crop was harvested and a new planting started in the same nutrient solution. This treatment was the typical end to end production of a single crop from planting to harvest, then repeating the sequence. The treatment was $5 \mathrm{~m}^{2}$ staggered production in which $1 / 4$ of the plants were harvested and replanted into the shared solution at 26-d intervals for the duration of the experiment. This simulated a continuous production system which would result in a consistent supply of product over the course of the trial. The experiment ran for a total of $418 \mathrm{~d}$ (four batch cycles of the control). 
Table 1. Crops grown in recirculating hydroponics as a part of NASA' Bioregenerative Life Support Program at Kennedy Space Center, Fla.

\begin{tabular}{|c|c|c|}
\hline Crop & Cultivar & Edible part \\
\hline Bean (Phaseolus vulgaris L.) & Etna, Hystyle & Seed, pod \\
\hline Carrot (Daucus carota L. ) & French Portima, Baby Mini, Lady Finger & Root \\
\hline Chard (Beta vulgaris L.) & Ruby Red Rhubarb & Leaf \\
\hline Lettuce (Lactus sativa L.) & $\begin{array}{l}\text { Waldmanns Green, Grand Rapids, Flandia, Ostinada, Red Sails, Outredeous, Eruption, Vivaldi, } \\
\text { Claremont, Little Gem }\end{array}$ & Leaf \\
\hline Onion (Allium fistulosum L.) & $\begin{array}{l}\text { Cippolini Barattana, Kinka, Guardsman, Deep Purple, Choetsu, Pacific Pearl, Choho, } \\
\text { Evergreen Hardy White, Kruncho }\end{array}$ & Leaf, bulb \\
\hline Peanut (Arachis hypgaea L.) & Florunner, Sunrunner, Georgia Early Bunch, Pronto & Seed \\
\hline Pepper (Capsicum annum L.) & Hanging Basket, False Alarm, Triton & Fruit \\
\hline Potato (Solanum tuberosum L.) & Norland; Denali, Russet Burbank & Tuber \\
\hline Radish (Raphanus sativus L.) & $\begin{array}{l}\text { Cherry Belle, Giant White Globe, Early Scarlet Globe, Cherriette, Vintage, Fireball, Cabernet, } \\
\text { Reggae, D’Avignon, Red Beret, Sora, Red Meat, Daikon, Shunkyo, Easter Egg, Sparkler, } \\
\text { Red Devil }\end{array}$ & Hypocotyl \\
\hline Red Beet (Beta vulgaris L.) & Ruby Queen, Red Ace, Monopoly, Klein Bol & Root, leaf \\
\hline Rice (Oryza sativa L.) & 29-LV-1, Ai Nan Tsio & Seed \\
\hline Soybean (Glycine max (L.) Merr.) & Hoyt; McCall, Pixie, Fiskoby V & Seed, pod \\
\hline Spinach (Spinacia oleracea L.) & Nordic IV & Leaf \\
\hline Strawberry (Fragaria $\times$ ananassa $)$ & Tristar, Tribute, Oso-Grande, Whitney, EV-3, Cavandish, Everest & Fruit \\
\hline Sweetpotato (Ipomoea batatas (L.) Lam) & TU-82-155, Georgia Jet, Maryland 320 & Root \\
\hline Tomato (Solanum esculantum L.) & Reinmann Philippe, Red Robin, Micro-Tom, Florida Petite & Fruit \\
\hline Wheat (Triticum aesativum $\mathrm{L}$ ) & Yecoro Rojo; Apogee; Veery 10; Super Dwarf & Seed \\
\hline
\end{tabular}
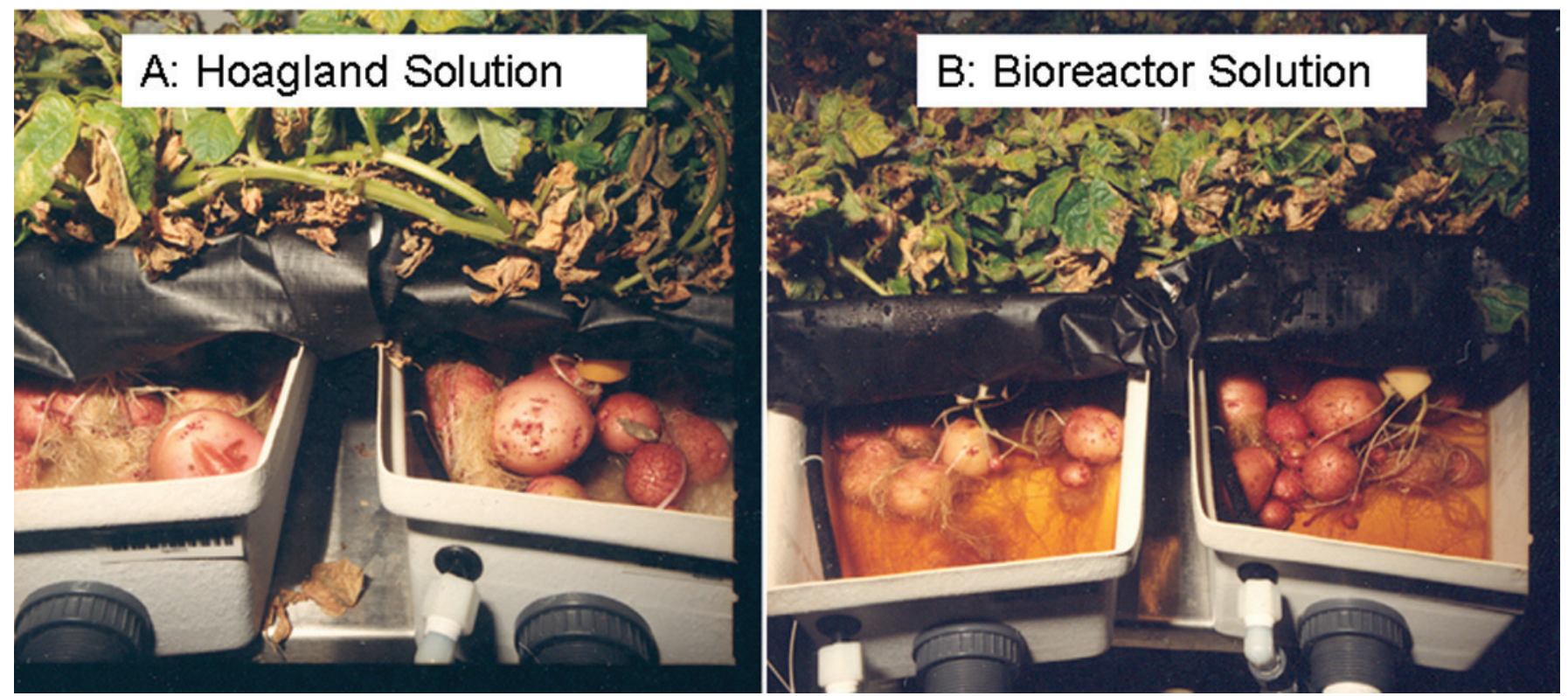

Fig. 1. Development of potato tubers in continuous culture using recirculating hydroponics. (A) 'Norland' potato (82-d-old) grown using modified Hoagland solution to supply nutrients. There was no pigmentation of the solution. (B) 'Norland' potato (82-d-old) grown using bioreactor effluent from leaves and stems of previous potato harvests to supply $50 \%$ of the total nutrients to a new crop. Notice the accumulation of recalcitrant compounds in the solution that impart coloration. There were no differences in yield between the two sources of nutrients and both treatments accumulated bioactive compounds that reduced the canopy height and accelerated tuber initiation.

\section{Materials and Methods}

'Norland' potato plantlets were transplanted into the growing trays of the BPC. All plants were grown using recirculating NFT culture as previously described (Wheeler et al., 1990). Potato was selected as the crop for this experiment since it had been demonstrated to grow well in hydroponic systems and had a high harvest index (Wheeler et al., 2003).

There were a total of four $5-\mathrm{m}^{2}$ growing levels in the BPC, each with an independent 200 Lnutrient solution reservoir that supported the recirculating NFT system. Two levels were grown in batch and two in staggered production. With each production system, one of the levels used stock nutrient solutions (Hoagland's solution) to supply essential elements, the other level had $50 \%$ of the nutrients recycled from the inedible biomass (leaves and stems) of previous harvests that had been processed though an aerobic bioreactor (Yorio et al., 1999). There were no differences in yield between the two nutrient sources (Mackowiak etal., 1997; Stutte et al., 1999), and the treatments are combined and treated as replicates (Fig. 1).

Environmental setpoints were maintained using a dedicated computer control system. These consisted of a $12 \mathrm{~h}$ light $/ 12 \mathrm{~h}$ dark photoperiod with a matching thermoperiod of $20 / 16$ $\pm 0.2{ }^{\circ} \mathrm{C}$ and constant relative humidity of $65 \%$ $\pm 6 \%$. Atmospheric $\mathrm{CO}_{2}$ concentrations were maintained at $1200 \pm 10 \mu \mathrm{mol} \cdot \mathrm{mol}^{-1}$ with an infrared gas analyzer (Licor, Lincoln, Neb.). No effort was made to control $\mathrm{CO}_{2}$ concentration during the dark cycle. The $\mathrm{pH}$ of the nutrient solution tank was controlled to $5.8 \pm 0.2$ by additions of dilute $(2.5 \%) \mathrm{HNO}_{3}$ and nutrient solution temperature was maintained at $18^{\circ} \mathrm{C}$ in all levels for the duration of the growout.
Solution electrical conductivity was controlled near $1.2 \mathrm{dS} \cdot \mathrm{m}^{-1}$ by additions of a complete nutrient replenishment solution. A summary of actual environmental conditions for both treatments is shown in Table 2.

The batch production treatment was in the upper chamber of the BPC. All 32 trays of the compartment were planted and harvested at 104- to 105-d cycles. Thus, the plants were all the same age during development. In the initial planting, each tray was thinned to 2 plants per tray $\left(8\right.$ plants $\left./ \mathrm{m}^{2}\right)$. In the second cycle, the density was increased to 3 plants per tray (12 plants $/ \mathrm{m}^{2}$ ) in anticipation of a reduction of total canopy area. This density was increased to 4 plants per tray (16 plants $/ \mathrm{m}$ ) in the third and fourth cycles. The nutrient solution was not changed following the harvests.

The staggered production treatment was in the lower chamber of the BPC. This treatment 
Table 2. Summary of environmental conditions for plant growth during the 418-d-test.

\begin{tabular}{|c|c|c|c|}
\hline Parameter & Setpoint & Batch treatment & Staggered treatment \\
\hline Photosynthetic photon flux ${ }^{z}$ & $300 \mu \mathrm{mol} \cdot \mathrm{m}^{-2} \cdot \mathrm{s}^{-1}$ & $303 \pm 58$ & $315 \pm 63$ \\
\hline Air temperature ${ }^{\mathrm{y}}$ & $20 / 16^{\circ} \mathrm{C}$ & $18.1 \pm 3.3^{x}$ & $18.0 \pm 2.3^{x}$ \\
\hline Relative humidity ${ }^{y}$ & $75 \%$ & $76 \pm 16$ & $74.5 \pm 15.2$ \\
\hline $\mathrm{CO}_{2}^{\mathrm{y}}$ & $1200 \mu \mathrm{mol} \mathrm{mol}^{-1}$ & $1361 \pm 393^{w}$ & $1346 \pm 363^{w}$ \\
\hline $\mathrm{pH}^{\mathrm{y}}$ & 5.8 & $5.75 \pm .25$ & $5.84 \pm .35$ \\
\hline $\mathrm{EC}^{\mathrm{y}}$ & $1.2 \mathrm{dS} \cdot \mathrm{m}^{-1}$ & $1293 \pm 484$ & $1317 \pm 516$ \\
\hline NDS temperature ${ }^{y}$ & $18^{\circ} \mathrm{C}$ & $18.1 \pm 1.5$ & $18.2 \pm 1.4$ \\
\hline
\end{tabular}

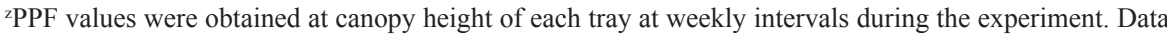
represent mean and SD for these weekly values during the 418-d test.

${ }^{y}$ Data from the control sensors was collected at 5-min intervals for the duration of the experiment. Data represent mean and SD for all the data collected during the 418-d test.

${ }^{x}$ Data represent mean of both the light and dark temperature cycles.

${ }^{\mathrm{w}} \mathrm{CO}_{2}$ was controlled during light cycle only.
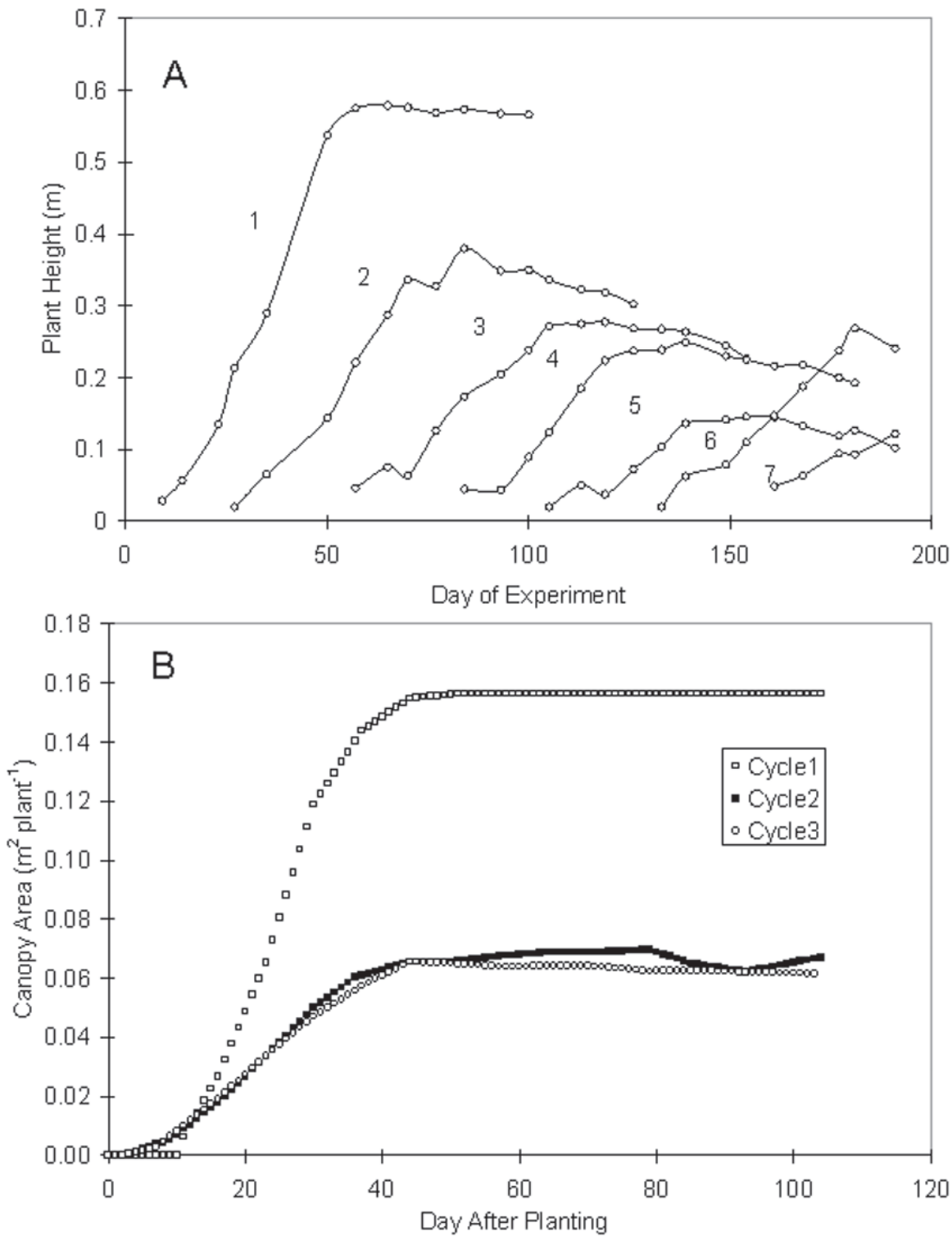

Fig. 2. Effects of aged solution on the growth of 'Norland' potato. (A) Height of potato plants grown using a 26-d staggered harvest/planting cycle. At Day 0, all plants were grown on fresh nutrient solution, and each successive cycle ( 1 to 7 ) represents the harvest of old plants, and the transplanting of new plantlets into the existing nutrient solution. With each successive planting there is a reduction in plant height reflecting the accumulation of bioactive materials in the solution. The partial recovery noted in cycle 7, reflects the overall reduction in total biomass, and presumed titer, of the bioregulator in the solution (B) Individual plant canopy coverage of Norland potato grown in sequential 104-d batch cycles in recirculating hydroponics. The initial planting cycle (Cycle 1) was planted into fresh Hoagland solution and the subsequent planting cycles (Cycles 2 and 3) were planted into aged nutrient solution. The accumulation of bioregulatory compounds in the nutrient solution during Cycle 1 impacted growth of new transplants. involved the harvest of 4 trays $(25 \%)$ from each level at 26-d intervals. The trays were replanted at a density of 4 plants/tray. There was a thinning at 14 DAP to 2 plants for tray in the initial planting. After the fourth replant cycle, there was no thinning of the plants, and the final density was maintained at four plants per tray. This was done in achieve full canopy coverage with the smaller plants. The nutrient solution was not changed following the harvests.

\section{Results}

Plants were shorter and canopy area smaller for each successive planting in the staggered production system (Fig. 2a). The reduction in plant height was accompanied by an earlier tuber initiation ( $21 \mathrm{vs} .28 \mathrm{~d}$ ) and maturation of the crop ( 84 vs. 104 d). After about six planting and harvest cycles, all the plants had less biomass and height began to marginally increase (Figs. 2a and 3). However, by increasing the density of the planting from 8 to 16 plants $/ \mathrm{m}^{2}$, the reduced height was sustained and yield per $\mathrm{m}^{2}$ was equal to or greater than that observed in the batch production.

After the initial harvest of the batch production system, a second planting was introduced into the aged nutrient solution. It too, exhibited a very striking and persistent reduction in plant height and canopy area that was accompanied by accelerated tuber initiation and early maturation of the crop (Fig. 2b).

Weekly microbial monitoring of the nutrient solution and root tissue revealed a diverse microbial population, but no known pathogenic organisms. No pathogenic fungi or bacteria were detected in leaf tissue. Weekly analysis of the nutrient solution allowed nutrient imbalances in the solution to be avoided. Leaf tissue analysis at each harvest did not reveal deficient or toxic nutrient levels (data not shown). These data suggested tha the growth response was not due to either a pathogen or nutrient imbalances in either the solution or the plant tissue.

A series of experiments were then performed using the nutrient solution produced in 418-d study. The first was the growth of potatoes under noninductive photoperiod conditions (night-break) to determine if the effect on growth was associated with reduced shoot height, earlier induction, or both. Potatoes grown on the aged BWP941 solution induced potatoes under these noninductive photoperiods while those grown on fresh Hoaglandsolution did not. The tuber inducing factor (TIF) could be removed by filtering the nutrient solution through activated carbon (Fig. 4). This experiment, as well as several others, indicated that an organic compound produced by the potato was having a direct effect on the differentiation and partitioning of potato (Stutte and Yorio 1998, 1999).

The change in growth response induced by the accumulation of the bioactive compound required changes in the crop management. The primary change was an increase in planting density from 8 to 16 plants $/ \mathrm{m}^{2}$ to achieve full canopy coverage for light interception. The 


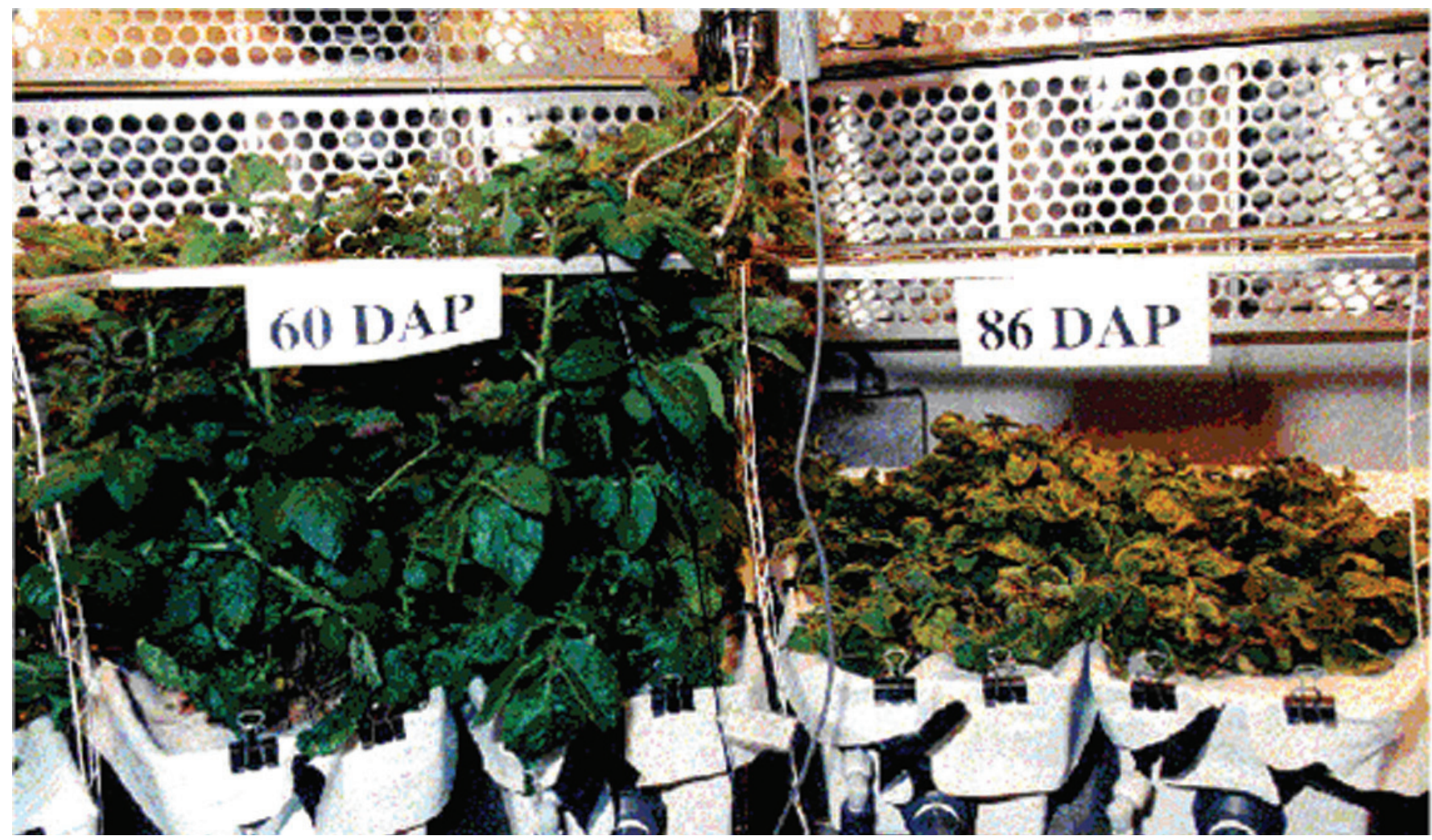

Fig. 3. 'Norland' potato $\mathrm{p}$ in the Biomass Production Chamber at Kennedy Space Center on recirculating hydroponic solution. The different aged plants are sharing a common nutrient solution and react to compounds produced directly from the potatoes or secondarily from microorganisms in the rhizosphere with each successive planting the autotrophic response to organic compounds in the shared solution that resulted in a reduction in plant height and canopy area.

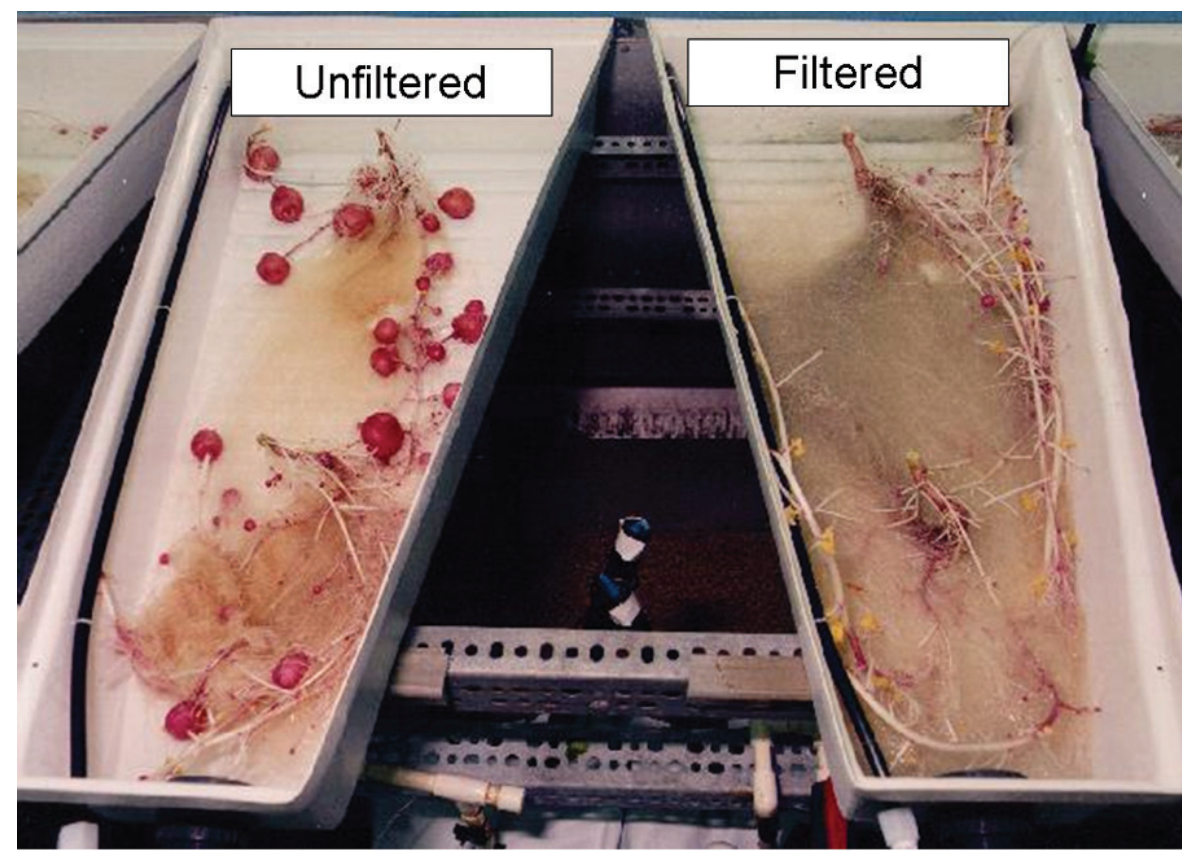

Fig. 4. 'Norland' potato after $42 \mathrm{~d}$ on either unfiltered or activated carbon filtered 0.5 strength Hoagland (control) solutions under a noninductive $(12 / 6+6)$ photoperiod. The unfiltered solution resulted in the induction of development of potatoes under noninductive photoperiods. There was also an associated reduction in plant height and canopy size. The removal of the organic compound with activated carbon filtering resulted in no tuber formation. Normal plant height and canopy volume were also restored by filtering.

TIF material can be removed from the nutrient solution with activated carbon filtering (Stutte and Yorio, 1999; Yorio et al., 2001), but were not implemented since the $76 \%$ reduction in control the titer of TIF in the solution since no timely monitoring approach for the compound exists at this time.

The accumulation of TIF presented several advantages for continuous production of potato, including reduction in plant height which decreases the cost of structures to grow the plants, accelerated harvest which increases the average daily yield by $20 \%$ (12.45 to $14.95 \mathrm{~g} \cdot \mathrm{m}^{-2} \cdot \mathrm{d}^{-1}$ tuber dry mass), and increased the harvest index from 59.2 to 86.5 . This means that the plant system was almost $50 \%$ more effective at converting the waste $\mathrm{CO}_{2}$ into edible biomass when grown on in a nutrient solution containing TIF (Stutte and Yorio, 1999, Stutte et al., 1999).

The use of a production system and/or natural product produced through such a process, would potentially benefit seed potato production by extending the season, decreasing the time, and increasing the yield in a recirculating system. Because of those benefits, the process for producing the vegetative and tuber growth regulator was patented (Stutte and Yorio, 1999).

It was subsequently discovered that TIF bioactivity was retained in concentrated material, allowing it to be reconstituted and added back to hydroponic systems. The screening of the dried material in seedling bioassays revealed that it altered the shoot to root ratio of several species other than potato (Edney et al., 2001). This suggests that the technique may have benefits beyond specialized potato production systems. As a result of this finding, both the Process (recirculating hydroponic production) used to produce potatoes and the Product (TIF containing solution/powder) 
from the process have been identified as new technologies and are being evaluated for commercial development.

\section{Impacts of Recirculating Hydroponics on Continuous Production}

The example with potato described above illustrates a number of issues associated with the use of recirculating hydroponics in sustained, long-duration production systems. The first is that recirculating hydroponics is an effective means of supplying water and nutrients that minimize water runoff and nutrient discharge while optimizing the nutrient requirements for an individual crop. This technique worked equally well with nutrients recovered from bioreactors or from stock reagents (Mackowiak et al., 1997, Stutte et al., 1999; Yorio et al., 1999). A second is that bioactive organic compounds from plant and the microbial sources may accumulate in the nutrient solution and induce unexpected growth responses that require active management (Stutte and Sager, 1995, Stutte and Yorio, 1999). Finally, the process itself may produce bioactive materials that have commercial value (Edney et al., 2001; Stutte and Yorio, 1999).

While there is a rich literature on the presence of allelopathic compounds in the soil, the presence and impact of these bioactive compounds in hydroponic systems is not well understood or researched (Cutler and Culter, 1999; Kaufman et al., 1999). It is not known whether high concentration of bioactive materials in the plant tissue (as in the case of medicinal crops) correlate with the accumulation of bioactive compounds in the nutrient solution and is an area requiring further investigation. It is also not known which phytochemicals that are biologically active in mammalian systems also have plant growth regulatory roles. While the literature is spotty, there are several instances of similar structures being used in both pharmaceutical and plant growth regulatory functions (Cutler and Cutler, 1999). However, the management of growth modifying bioactive materials to enhance productivity may be an unanticipated benefit of growing phytochemical rich plants in recirculating hydroponics.

In conclusion, the use of recirculating hydroponics for the long-term production of many crops has been demonstrated. The accumulation of bioactive organic compounds during sustained crop production in recirculating hydroponic systems may require that adaptations to the production system be used to either negate negative effects of allelopathic compounds or to exploit improvements in cropping efficiency. The types of compounds that accumulate in the nutrient solution need to be identified and the potential use of these natural products for plant growth regulators, pest control, or medicinal supplements carefully considered.

\section{Literature Cited}

Berry, W.L. and S. Knight. 1997. Plant culture in hydroponics. In: R.W. Langhans and T.W. Tibbitts (eds.). Plant growth chamber handbook. Iowa Agr. Home Econ. Expt. Sta., Ames.

Cutler, H.G. and S.J. Cutler. 1999. Agrochemicals and pharmaceuticals: The connection, p. 1-14. In: H.G. Cutler and S.J. Cutler (eds.). Biologically active natural products: Agrochemicals. CRC Press, Boca Raton, Fla.

Edney, S.L., N.C. Yorio, and G.W. Stutte. 2001. Evaluation of a potential potato tuber-inducing factor on seedling growth of several species. Proc. Plant Growth Regulat. Soc. Amer. 28: 94-96.

Gaspar, E.M., H.J. Chaves das Neves, and M Manuela A. Periera. 1999. Triterpenoids and other potentially active compounds from wheat straw: Isolation, identification, and synthesis, p. 69-80. In: H.G. Cutler and S.J.Cutler (eds.). Biologically active natural products: Agrochemicals. CRC Press, Boca Raton, Fla.

Goins, G.D, N.C. Yorio, G.W. Stutte, R.M. Wheeler, and J.C. Sager. 2003. Baseline environmental testing of candidate salad crops with horticultural approaches and constrains typical of spaceflight. Soc. Agr. Eng. Tech. Paper 2003-01-2481.

Graves, C.J. 1983. The nutrient film technique. Hort. Rev. 5:1-44.

Halstead, T.W. and F.R. Dutcher. 1987. Plants in space. Annu. Rev. Plant Phys. 38:317-345.

Hoff, J.E, J.M. Howe, and C.A. Mitchell. 1982. Nutritional and cultural aspects of plant species selection for a controlled ecological life support system. NASA Contractor Rpt. 166324.

Kaufman, P.B., L.J. Cseke, S. Worber, J.A. Duke, and H.L. Brielman. 1999. Natural products from plants. CRC Press, Boca Raton, Fla.

Mackowiak, C.L., J.L. Garland, and G.W. Stutte. 1994. Growth regulator effects of water soluble materials from crop residues for use in plant hydroponic culture. Proc. Plant Growth Regulat. Soc. Amer. 22:233-239

Mackowiak, C.L., P.R. Grossel, and B.G. Bugbee. 2001. Beneficial effects of humic acid on micronutrient availability to wheat. Soil Sci 65:1744-1750.

Mackowiak, C.L., R.M. Wheeler, G.W. Stutte, N.C. Yorio, and J.C. Sager. 1997. Use of biologically reclaimed nutrients for continuous hydroponic potato production in a CELSS. Adv. Space Res. 20:1815-1820.

Miller, R.L., and C.H. Ward. 1966.Algal bioregenerative systems. In: E. Kammermeyer (ed.). Atmosphere in space cabins and closed environments. Appleton-Century-Croft, New York.

Myers, J. 1954. Basic remarks on the use of plants as biological gas exchangers in a closed system. J. Aviation Med 35:407-411.
Prince, R.P. and W.M. Knott. 1989. CELSS Breadboard Project at the Kennedy Space Center. In: D.W. Ming and D.L. Henninger (eds.). Lunar base agriculture: soils for plant growth. Amer. Soc. Agron., Madison, Wis.

Resh, H.M, 1989. Hydroponic food production. $4^{\text {th }}$ ed. Woodbridge Press, Santa Barbara, Calif.

Salisbury, F.B. and M.A.Z. Clark. 1996. Choosing plants to be grown in a controlled environment life support system (CELSS) based upon attractive vegetarian diets. Life Support Biosphere Sci. 2:169-179.

Stutte, G.W. 1999. Implications for long duration space missions, p. 275-286. In: H.G. Cutler and S.J. Cutler(eds.). Biologically active natural products: Agrochemicals. CRC Press, Boca Raton, Fla.

Stutte, G.W., C.L. Mackowiak, N.C. Yorio, and R.M. Wheeler. 1999. Theoretical and practical considerations of staggered crop production in a BLSS. Life Support Biosphere Sci. 6:287-291.

Stutte, G.W. and J. C. Sager. 1995. Biological considerations in the design of continuous potato production systems. Amer. Soc. Agr. Eng. Tech. Paper 9555654.

Stutte, G.W. and N.C. Yorio. 1998. Biological activity of a vegetative and tuber growth regulator obtained from recirculating hydroponics. Proc. Plant Growth Regulat. Soc. Amer. 25:179-180.

Stutte, G.W. and N.C. Yorio. 1999. Process for producing vegetative and tuber growth regulator. US. Patent 5,992,090.

Tibbitts, T.W. and D.K. Alford. 1982. Controlled ecological life support system: Use of higher plants. NASA Conf. Publ. 2231.

Wheeler, R.M, C.L. Mackowiak, J.C. Sager, W.M. Knott, and C.R. Hinkle. 1990. Potato growth and yield using nutrient film technique. Amer. Potato J. 67:177-178

Wheeler, R.M., C.L. Mackowiak, G.W. Stutte, J.C. Sager, N.C. Yorio, L.M. Ruffe, R.E. Fortson, T.W. Dreschel, W.M. Knott, and K.A. Corey. 1996. NASA's biomass production chamber: A testbed for bioregenerative life support studies. Adv. Space Res. 18:215-224

Wheeler, R.M., J.C. Sager, R.P. Prince, W.M. Knott, C.L. Mackowiak, G.W. Stutte, N.C. Yorio, L.M Ruffe, B.V. Peterson, G.D. Goins, C.R. Hinkle, and W.L. Berry. 2003. Crop production for advanced life support systems: Observations from the Kennedy Space Center Breadboard Project. NASA TM 2003-211184.

Wheeler, R.M. G.W. Stutte, G.V. Subbarao, and N.C. Yorio. 2001. Plant growth and human life support for space travel. p. 925-941. In: M. Pessarakli (ed.). $2^{\text {nd }}$ ed. Handbook of plant and crop physiology. Marcel Dekker Inc., New York

Yorio, N.C., M.P. Alazraki, J.L. Garland, T.H. Englert, and L.M. Ruffe. 1999. The utilization of recovered nutrients from composted inedible biomass to support plant growth for BLSS. Soc. Agr. Eng. Tech. Paper 1999-01-2062.

Yorio, N.C., G.W. Stutte, F.J. Troendle, and S.L.Edney. 2001. Anaturally occurring vegetative growth and tuber-inducing factor accumulates in hydroponic nutrient solution of potato. Proc. Plant Growth Regulat. Soc. Amer. 28:101-103. 